\title{
Active Lifestyle Among Pregnant Women in Burundi
}

\author{
Ngayimbesha Adrien, Bizimana Jean Berchmans, Gakima Marie Stella, Nzisabira Félix
}

Institut d'Education Physique et des Sports, Université du Burundi, Bujumbura, Burundi

\section{Email address:}

adrienngayimbesha@yahoo.fr(N. Adrien)

\section{To cite this article:}

Ngayimbesha Adrien, Bizimana Jean Berchmans, Gakima Marie Stella, Nzisabira Félix. Active Lifestyle Among Pregnant Women in Burundi. American Journal of Sports Science. Vol. 6, No. 3, 2018, pp. 74-77. doi: 10.11648/j.ajss.20180603.11

Received: October 12, 2017; Accepted: October 25, 2017; Published: May 8, 2018

\begin{abstract}
Anatomical and physiological changes during pregnancy can alter balance, coordination capabilities and finally make some activities more uncomfortable. The present study used self-administrated questionnaire to assess Burundi's pregnant women physical practice level and their knowledge regarding health benefits of physical exercise practice during pregnancy. Study outcomes show majority of Burundi women adopt sedentary lifestyle during pregnancy, and they have a negative apprehension on exercise and physical activity practice during pregnancy.
\end{abstract}

Keywords: Pregnant Women, Lifestyle, Burundi

\section{Introduction}

Unless complications, Pregnancy is a natural condition rather than an illness. However, there are many anatomical and physiological changes during pregnancy. One of them is an increase in body weight with its effect on functional capability of the pregnant woman. In fact, as pregnancy progresses, Weight increases and changes occur in weight distribution and body shape.

This results in the body's center of gravity moving forward and the curvature of the spine increasing. This increase in body size can make some activities more uncomfortable.

These changes can also alter balance and co-ordination, particularly in the second half of the pregnancy. All these problems potentially caused by the excess weight gain during pregnancy can be prevented or where managed by an active life style [1]. Studies showed many good health outcomes of exercise practicing during pregnancy.

Evidence-based guidelines indicate that regular physical activity in pregnancy is a basic precondition of its course [2].

Physical activity during this period, similar to the time of not being pregnant, is a basis for the maintenance of the musculoskeletal system on an adequate level and prevents the development of many disorders, such as varicose veins of the lower extremities, deep venous thrombosis or lumbar spine pain.

There is much evidence that regular exercise in the prenatal period is an important element of treatment and prevention of gestational diabetes, preeclampsia and obesity in the mother, and resulting from this, implications for the course of pregnancy, type of pregnancy termination and the state of newborns after birth [3]. Physical exercises are currently considered as supportive therapy for women with gestational diabetes [4]. There is evidence that women who were physically active before becoming pregnant, more rarely contracted gestational diabetes during pregnancy. A regular physical exercise in an early period of pregnancy stimulates placental growth and prevents its pathophysiological changes, which may the cause of preeclampsia [5]. Lack of exercise during pregnancy might result in loss of muscular and cardiovascular fitness, excessive maternal weight gain with a raised risk of GDM, varicose veins, dyspnea, lower back pain and poor psychological adjustment [6].

Take all advantages of active life style to maternity highlighted by researchers, it is evident that in the absence of medical or obstetrical complications, pregnant women are encouraged to continue and maintain active lifestyles during their pregnancies.

However, most pregnant women are less active during pregnancy [7]. In developed countries, level of physical exercise practice has been well documented. In underdeveloped countries like Burundi, there is no documentation or statistics showing the state of physical exercise practice of our mothers during pregnancy. Are them well knowledgeable about health outcomes from physical exercising during pregnancy? What are their attitudes with 
respect to physical exercise in pregnancy?

The present study will attempt to respond to these questions and situate Burundi's pregnant women state of physical exercise practice.

\section{Method}

\subsection{Participant to the Study}

A Total number of one hundred and fifty pregnant women have been recruited to participate to the present study. Among them, one half of participant women were from rural area, and the other half from urban area. All these pregnant women were attending antenatal care in different hospitals at the time of the research. Their ages were between 18 and 40 .

\subsection{Assessment of Their Level on Physical Activity}

A self-administrated questionnaire was used to collect data necessary to the present study. This questionnaire was divided into three parts: demographic data in the first part, exercise practice in the second part of the questionnaire and Information received during their antenatal visit in the third part. Concerning exercise practice, women were not questioned on their sedentary activities such as watching television, reading or sewing. They were questioned about the types of physical activity they often engaged in, the frequency (how many times a week), its duration (how many minutes or hours their usually engaged in particular activity).

\subsection{Statistical Analysis}

Collected data has been analyzed using statistical package for social science (SPSS) version 17. The analysis was mainly oriented to identify any relationship between demographic with level of physical activity among our pregnant women. Associations were evaluated by Chi Square Test. $\mathrm{P}$ value of less than 0.05 was considered significant.

\subsection{Ethical Consideration}

Ethical approval was obtained from the Ethic Committee of the Faculty of Medicine, University of Burundi.

\section{Results}

Demographic characteristics assessed in the present study are: age of participants, the evolution stage of their pregnancy and their educational background. The mean age of our participant was 28.3 years. Few of participant attained University level 12\% $(n=18)$.

Table 1. Demographic characteristics of participants.

\begin{tabular}{lll}
\hline Characteristics & Frequency & Percentage \\
\hline Age & & \\
$18-25$ & 23 & $15.3 \%$ \\
$26-30$ & 57 & $38 \%$ \\
$31-35$ & 49 & $32.6 \%$ \\
$36-40$ & 21 & $14 \%$ \\
\hline
\end{tabular}

\begin{tabular}{lll}
\hline Characteristics & Frequency & Percentage \\
\hline Stage of pregnancy & & \\
First term of pregnancy & 67 & $44.6 \%$ \\
Second term of pregnancy & 35 & $23.3 \%$ \\
Third term of pregnancy & 48 & $32 \%$ \\
Educational background & & \\
Elementary level & 85 & $56.6 \%$ \\
College level & 47 & $31.3 \%$ \\
University level & 18 & $12 \%$ \\
\hline
\end{tabular}

A big majority of participant pregnant women $88 \%$ $(n=132)$. For the exercising duration, responded to engage in physical exercise once time a week $55 \%$ of participant pregnant women $(n=87)$ responded that they took $s$ at least 30minutes exercise their bodies and the common physical exercise used by our pregnant women is housekeeping activity.

Table 2. Exercise practice during pregnancy.

\begin{tabular}{lll}
\hline Exercise during pregnancy & Frequency & Percentage \\
\hline Frequency & 132 & $88 \%$ \\
One a week & 11 & $7.3 \%$ \\
Twice a week & 7 & $4.6 \%$ \\
Three times a week & - & - \\
More than three times a week & & \\
Exercising duration & 48 & $32 \%$ \\
10 minutes one session & 12 & $8 \%$ \\
20 minutes one session & 87 & $58 \%$ \\
30 minutes one session & 3 & $2 \%$ \\
More than 30 minutes one session & & \\
Type of exercise & 48 & $32 \%$ \\
Walking & - & - \\
jogging & 6 & $4 \%$ \\
swimming & - & - \\
Riding on stationary bicycle & 92 & $61.3 \%$ \\
Housekeeping activity & 4 & $2.6 \%$ \\
Stair climbing & & \\
\hline
\end{tabular}

According to the present study results majority of our participant has a very bad apprehension on sports and physical exercise during pregnancy. In fact, $84.6 \%$ judge physical exercise harm to pregnant mother and the foetus $(n=127)$.

Table 3. Judgment of physical exercise effect on health.

\begin{tabular}{lll}
\hline Judgment & Frequency & Percentage \\
\hline Safe and benefit for Pregnant mother & 23 & $15.3 \%$ \\
Safe and benefit for foetus & 23 & $15.3 \%$ \\
Harmful to pregnant mother & 127 & $84.6 \%$ \\
Harmful to the foetus & 127 & $84.6 \%$ \\
\hline
\end{tabular}

Is there any association between our participant pregnant demographic characteristics with their exercise practice?

Statistical analysis showed a significant association between educational background with exercise practice $(P$ Value obtained is 0.003 ) while there is no significant association found between stage of pregnancy $(P>0.05)$. In addition, age factor was found associated to exercise practice ( $P$-Value obtained was 0.004$)$. 
Table 4. Association between demographic characteristic and exercise practice.

\begin{tabular}{lll}
\hline Demographic characteristics & X2 (Chi2) & P-Value \\
\hline Age & 6.9321 & 0.034 \\
Stage of pregnancy & 5.2541 & 0.07 \\
Educational background & 9.8242 & 0.003 \\
\hline
\end{tabular}

\section{Discussion}

Outcomes of the present study showed that our participant pregnant women, taken together can be classified in sedentary lifestyle. In fact, $88 \%$ of them $(n=132)$ exercise their bodies once time a week. This frequency is very far below international recommendations regarding frequency of physical activity: The American college of Sports Medicine recommended a frequency of 5 times of physical exercise per week [8]. Exercise doing at this frequency can be highly beneficial not only to pregnant women but also to any person engaged in this type of active life style. In addition our study results showed that their exercising intensity (30minutes per session for majority) can be acceptable and is in the range of international recommendation [8]. However, the efficient benefit of exercise on health results of a good combination of significant frequency and intensity of physical training. For our pregnant women participated in the present study results has showed a too low frequency among them. This bad combination of frequency and intensity significantly compromise the good outcomes of physical exercise on health of pregnant women. The present study findings regarding physical exercise practice during pregnancy are in agreement with other studies such as the study carried out in Pakistan [9] in which the prevalence of exercise use during pregnancy was low (20\%). The present study findings are also in agreement with other studies conducted in Brazil such as that carried out in São Paulo assessing Brazilian pregnant women's knowledge, attitudes and practices on physical exercise. Researchers found that a very small percentage of Brazilian pregnant women exercise their bodies during pregnancy [10]. Another study conducted in Ireland on the prevalence of physical activity among healthy pregnant women arrived to similar results [11]. In fact an assessment of levels of physical activity in a cohort of healthy women in Ireland, who had no contraindications to exercise during pregnancy, found that only $21.5 \%$ women met the current recommendations for exercise in pregnancy. An alarming data regarding sedentary lifestyle among Brazilian pregnant women has been reported [12]. A systematic review on physical exercise during pregnancy reported that $4.7 \%$ of Brazilian women adopt sedentary lifestyle while $12.9 \%$ is reported to engage in some types of physical activity during pregnancy. The present study has found an association between sport exercise and educational background among our participant. This result is quite similar to what reported in Lusaka Zambia [13]. In Burundi, similar to many other African countries like Zambia the educational level among general population still low. Take gender in consideration female educational level become very low. This low educational level among our pregnant women negatively affects women knowledge on sport exercise and as consequence their willingness to take part in exercise practice becomes low particularly during pregnancy. However, the present study result regarding association between sport exercise and educational background among our participant is different from what was reported in Brazil [14]. In this Brazil study, no significant statistical association was found between level of education and exercise practice among pregnant women in Brazil. Brazil country is a developing country with an educational level high than Burundi's. This difference in educational level may explain the difference observed.

Moreover, study results has showed that almost all participants, $61.3 \%(\mathrm{n}=132)$ engaged in similar activities "housekeeping activity domain" as way of exercise. This result is similar to a study results conducted in Sri Lanka [15] Walking was the other type of exercise practice preferred by our participants in the study. This is again similar to study results from Sri Lanka.

The present study found again a signification association between exercise practice and age factor. Our participant age ranged between 18 years old and 40 years old. In this stage of age, beside physiological and anatomical changes which can decrease personal fitness, pregnant women can easily do exercise. However this is accepted in absence of obstetrical pathology. Participant to the present study responded that exercise practice during pregnancy can be harmful to the mother and also to the foetus. This negative apprehension regarding exercise practice during pregnancy is completely inadequate. The evidence is that their noninvolvement in exercise practice during pregnancy is based on the safety concerns. In contrast, researchers from Brazil reported that most women were adequately informed about the practice of physical exercise during pregnancy and significant associations were found between adequate knowledge of physical exercise during pregnancy and their education level [16]. The few pregnant women who responded that exercise practice during pregnancy were also inadequately informed on how to exercise their bodies, at which intensity and which frequency. It becomes evident that during their antenatal clinics, pregnant women were not well advised on the ideal antenatal exercise and on its health benefit outcomes. The antenatal health talks have focus on HIV/AIDS transmission and modes of prevention, nutrition, and immunization after getting baby. Some of these ideal antenatal exercises include: swimming, low-impact aerobic exercises, walking, jogging, indoor stationary bicycling...

The poor knowledge on antenatal excise practice has been found in Nigerian research [17]. This poor knowledge is worsened by the absence of Burundi Guidelines of physical activity during pregnancy. A study done in South Africa reported that women were willing to follow a set of guidelines with supervision [18]. Same as these South African Pregnant women, Burundi pregnant women may also follow established guidelines of physical activities if it becomes to benefit of them. Also exercise education should be a priority in antenatal care to adequately inform women on exercise practice and benefits during pregnancy. Physiotherapists should be integrated in the antenatal and reproductive health care programs to provide information and 
training on exercise activities ideal for pregnancy, because they are professionals in this area and can make meaningful contributions in reproductive health care provision.

The present study result didn't find any association between maternal physical activities paired to gestational evolution. This is inconsistent with study result from Sri Lanka [19] and from USA [20]. These two researchers have addressed solely one type of physical activity (vigorous physical activity) instead of assessing physical activity as a whole. However, our study results agree with a systematic analysis of 3313 articles in which the overall findings have indicated no apparent association between maternal physical activity and gestational age [21].

\section{Conclusion}

The purpose of the present study was to identify the level of physical practice among Burundi pregnant women and to evaluate their knowledge regarding health benefits of physical exercise practice during pregnancy. Considering the present study results it is clear that majority of Burundi pregnant women adopt sedentary life style during pregnancy. Walking and household chores during pregnancy constitute one type of physical exercise they usually engaged in. In addition, according to data gathered by the present study Burundi pregnant women have a negative apprehension on exercise and physical activity practice during pregnancy.

\section{References}

[1] Melanie, S.; Poudevigne; Patrick, J. O’Cannor 2005. Physical Activity and Mood during Pregnancy. Medecine and Science in Sports Exercise. American College of Sports Medecine.

[2] Davies GA, Wolfe LA, Mottola MF, MacKinnon C. 2003. Society of Obstetricians and gynecologists of Canada, SOGC Clinical Practice Obstetrics Committee. Joint SOGC/CSEP clinical practice guideline: exercise in pregnancy and the postpartum period. Can J Appl Physiol 28 (3): 330-41.

[3] Weissgerber TL, Wolfe LA, Davies GA, Mottola MF. 2006. Exercise in the prevention and treatment of maternal-fetal disease: a review of the literature. Appl Physiol Nutr Metab 31 (6): 661-74.

[4] Dempsey JC, Butler CL, Sorensen TK, Lee IM, Th ompson ML, Miller RS, Frederick IO, Williams MA. 2004. A casecontrol study of maternal recreational physical activity and risk of gestational diabetes mellitus. Diabetes Res Clin Pract 66 (2): 203-15.

[5] Saftlas AF, Logsden-Sackett N, Wang W, Woolson R, Bracken MB. 2004. Work, leisure-time physical activity, and risk of pre-eclampsia and gestational hypertension. Am J Epidemiol 160 (8): 758-65.

[6] Colberg SR, Castorino K, Jovanovič L 2013. Prescribing physical activity to prevent and manage gestational diabetes. World J. Diab. 15: 4 (6): 256-62.

[7] Piravej K and Sakisirinukul R 2001. Survey of exercise patterns, attitudes and the general effects of exercise during pregnancy in 203 Thai Women at King Chulalongkorn.
[8] Haskell, William, L., et all. 2007. Physical activity and public health: updated recommendation for adult from the American College of Sport Medicine and American Heart Association.

[9] Sarfraz M., Deeba I., Unaiza H., Syed H., Farah A. 2013. Role of physical therapy in antenatal care as perceived by the clients. A cross sectional survey on pregnant females attending antenatal OPD. Pakistal Journal of medicine and dentistry Voll (01): 34-46.

[10] Camen p., Riberio and Helaine M. 2011. Knowledge, attitudes and practice of women in Campinas, Sao Paulo, Brazil with respect to physical exercise during pregnancy: a descriptive study. Reproductive-health journal.

[11] Walsh J.M., McGowan C., Byrne J., McAuliffe F. M. 2011. Prevalence of physical activity among healthy pregnant women in Ireland. International Journal of Gynaecol. Obstetric.

[12] Simony L., Nascimento, Fernanda G., Surita, Jose G. 2012. Physical exercise during pregnancy: a systematic review. Curr. Opin. Obstet. Gynaecol Journal.

[13] Loveness A. Nkhata, Esther Munalula-Nkandu, Hastings Shula 2015. Exercise Practice Among Women Attending Antenatal Care at the University Teaching Hospital in Lusaka, Zambia. Science Journal of Public Health. Vol. 3, No. 3, pp. 361-365.

[14] Duncombe D, Wertheim E. H, Skouteris H, Paxton S. J, and Kelly L, 2009. Factors related to exercise over the course of pregnancy including women's beliefs about the safety of exercise during pregnancy. Midwifery, 25 (4), 430-438.

[15] Oshadijayakodyi, Hermantha Senanayake 2015. Effects of physical activity during pregnancy on birth outcomes in mothers presenting at the antenatal clinic of De Soysa maternity hospital, Colombo Srilanka.

[16] Ribeiro C. P and Milanez H. 2011. Knowledge, attitude and practice of women in Campinas, São Paulo, Brazil with respect to physical exercise in pregnancy: a descriptive study. Reproductive Health, 8 (1), 1-7.

[17] Mbada C. E, Adebayo O. E, Adeyemi A. E, Arije O. O, Dada O. O, Akinwande O. A, Awotidebe, T. O and Alonge I. O 2014. Knowledge and Attitude of Nigerian Pregnant Women towards Antenatal Exercise: A Cross-Sectional Survey. ISRN Obstetrics and Gynecology, Article ID 260539, 1-8.

[18] Muzigaba M, Kolbe-Alexander TL, Wong F 2014. The perceived role and influencers of physical activity among pregnant women from low socioeconomic status communities in South Africa. J. Phys. Act Health 11 (7): 1276-83.

[19] Dabrowska, MT, Siedlecka, J, Wlodarczyk, RZ, Włodarczyk, KW 1997. The Effect of Mothers' Occupation on Body Mass of Newborns Born at Term. MedycynaPracy, vol. 48, no. 4, pp. 381-92.

[20] Strenfeld, B, Quesenberry, CP, Eskenazi, B\&Newman, LA 1995. Exercise During Pregnancy and Pregnancy Outcome. Medicine and Science on Sports and Exercise, vol. 27, no. 5, pp. 634-40.

[21] Schlüssel,MM, De Souza, EB, Reichenheim, ME\&Kac, G 2008. Physical Activity During Pregnancy And MaternalChild Health Outcomes: A Systematic Literature Review. Cadernos de SaúdePública, vol. 24, pp. 531-44. 